\title{
Pemberdayaan Peternak dalam Teknologi Produksi Pupuk Organik dan Biogas di Desa Gedong dan Desa Gemawang Kecamatan Ngadirojo, Kabupaten Wonogiri
}

\author{
Shanti Emawati ${ }^{1,3 *}$, Suwarto ${ }^{2}$, Endang Tri Rahayu ${ }^{1,3}$ dan Sudiyono ${ }^{1,3}$ \\ ${ }^{1}$ Program Studi Peternakan, Fakultas Pertanian, Universitas Sebelas Maret, Surakarta, Indonesia; ${ }^{2}$ Program Studi \\ Penyuluhan dan Komunikasi Pertanian, Fakultas Pertanian, Universitas Sebelas Maret, Surakarta, Indonesia; \\ ${ }^{3}$ Pusat Penelitian dan Pengembangan Pangan Gizi dan Kesehatan Masyarakat, LPPM Universitas Sebelas Maret, \\ Surakarta, Indonesia
}

Diterima: 4 Maret 2020; Disetujui: 22 April 2020

\begin{abstract}
Abstrak
Kecamatan Ngadirojo merupakan salah satu sentra pengembangan usaha sapi potong di Kabupaten Wonogiri. Namun usaha yang dilakukan peternak belum menghasilkan pendapatan secara optimal. Tujuan dari kegiatan pengabdian ini adalah memberdayakan peternak dengan peningkatan pengetahuan peternak melalui aplikasi teknologi produksi pupuk organik berbasis limbah kotoran ternak sapi potong dan biogas sehingga dapat meningkatkan pendapatan peternak. Metode kegiatan pengabdian ini adalah melalui FGD (Focus Group Discussion), penyuluhan, pelatihan serta demplot mengenai teknologi produksi pupuk organik dan biogas. Hasil dari kegiatan ini adalah terjadi peningkatan pengetahuan peternak setelah mengikuti penyuluhan dan pelatihan tentang teknologi produksi pupuk organik dan biogas. Peternak di Desa Gemawang dan Desa Gedong Ngadirojo telah merasakan manfaat adanya pembangunan instalasi biogas dan kegiatan pengolahan limbah kotoran ternak menjadi pupuk organik. Kesimpulan dari kegiatan ini adalah upaya pemberdayaan melalui kegiatan penyuluhan dan pelatihan tentang pengolahan limbah ternak menjadi pupuk organik dan biogas menunjukkan keberhasilan dan berjalan efektif yang terlihat dari meningkatnya pengetahuan responden setelah mengikuti kegiatan penyuluhan dan pelatihan.
\end{abstract}

Kata kunci: biogas; pengetahuan; pupuk organik; sapi potong

\section{Farmer Empowerment in Organic Fertilizer Production Technology and Biogas in Gedong Village and Gemawang Village, Ngadirojo Sub-district, Wonogiri District}

\begin{abstract}
Ngadirojo District was one of the centers of beef cattle business development in Wonogiri Regency. But the business done by farmers has not yet produced an optimal income. The purpose of this service activity was to empower farmers by increasing farmers' knowledge through the application of organic fertilizer-based fertilizer production technologies for beef cattle manure and biogas waste so as to increase the income of farmers. The method of this community service activity was through FGD (Focus Group Discussion), counseling, training and demonstration plots on technology for organic fertilizer and biogas production. The result of this activity was an increase in knowledge of farmers after attending counseling and training on organic fertilizer and biogas production technology. Farmers in Gemawang and Gedong Ngadirojo villages have benefited from the construction of biogas installations
\end{abstract}

* Corresponding author: shantiemawati@staff.uns.ac.id

Cite this as: Emawati, S., Suwarto, Rahayu, E. T., \& Sudiyono. (2020). Pemberdayaan Peternak dalam Teknologi Produksi Pupuk Organik dan Biogas di Desa Gedong dan Desa Gemawang Kecamatan Ngadirojo, Kabupaten Wonogiri. AgriHealth: Journal of Agri-food, Nutrition and Public Health, 1(1), 14-21. doi: http://dx.doi.org/10.20961/agrihealth.v1i1.40449 
and the processing of livestock waste into organic fertilizer. The conclusion of this activity was the effort of empowerment through counseling activities and training on processing livestock waste into organic fertilizer and biogas showing success and running effectively as seen from the increasing knowledge of respondents after participating in counseling and training activities.

Keywords: beef cattle; biogas; knowledge; organic fertilizer

\section{PENDAHULUAN}

Kecamatan Ngadirojo merupakan salah satu kecamatan yang berada di Kabupaten Wonogiri dengan luas wilayah sebesar 9.325.556 ha yang terbagi menjadi 11 desa/kelurahan. Jumlah penduduk di Kecamatan Ngadirojo sebanyak 53.551 jiwa, terdiri dari 26.253 jiwa penduduk laki-laki dan 27.298 jiwa penduduk perempuan. Secara administratif Kecamatan Ngadirojo mempunyai batas-batas wilayah yaitu sebelah utara berbatasan dengan Kabupaten Karanganyar, sebelah selatan berbatasan dengan Kecamatan Nguntoronadi, sebelah barat berbatasan dengan Kecamatan Wonogiri dan sebelah timur dengan Kecamatan Sidoharjo (BPS Wonogiri, 2016).

Kecamatan Ngadirojo merupakan wilayah yang berpotensi dalam pengembangan usaha sapi potong, khususnya di Desa Gedong dan Desa Gemawang. Pengembangan sapi potong di Desa Gedong dan Desa Gemawang dilakukan dengan pembentukan Kelompok Tani Ternak (KTT). KTT Jati Galih dan KTT Sumber Rejeki merupakan KTT yang bergerak pada usaha penggemukan sapi potong dengan rata-rata kepemilikan 2-5 ekor.

Usaha peternakan sapi potong baik penggemukan maupun pemeliharaan induk penghasil pedet dapat dipastikan menghasilkan limbah kotoran feses dan urin. Setiap ekor sapi setiap hari menghasilkan feses segar sebanyak $15-20 \mathrm{~kg}$ dan 10-15 1 urin (Sunarto dan Lutojo, 2008). Pada usaha penggemukan selama 4 bulan diperoleh limbah feses sebesar 1.800-2.400 kg feses segar dan 1.200-1.800 1 urin, sedangkan pada usaha pemeliharaan induk sapi penghasil pedet rata-rata 12 bulan diperoleh feses segar sebesar $5.400 \mathrm{~kg}$ dan urin 3.600-5.400 1 urin sapi (Riyanto et al., 2010).

Beberapa permasalahan yang dihadapi peternak yang tergabung dalam KTT Jati Galih dan KTT Sumber Rejeki antara lain peternak belum memanfaatkan secara optimal limbah kotoran ternak sebagai pupuk organik dan biogas, rendahnya produksi tanaman pertanian dan tanaman pakan baik kuantitas maupun kualitas akibat penggunan pupuk kimia oleh peternak dan limbah ternak yang tidak diolah peternak menimbulkan pencemaran lingkungan sehingga mempengaruhi kesehatan ternak sapi potong yang berakibat produktivitas ternak menjadi rendah.

Kotoran ternak menyimpan potensi sebagai bahan baku utama biogas, karena keduanya merupakan bahan organik yang mempunyai kandungan Nitrogen $(\mathrm{N})$ tinggi, di samping unsur Karbon (C), Hidrogen (H), dan Oksigen. Kotoran sapi yang tersusun dari feses, urin, dan sisa pakan mengandung nitrogen yang lebih tinggi dari pada yang hanya berasal dari feses. Jumlah nitrogen yang dapat diperoleh dari kotoran sapi dengan total bobot badan $\pm 120 \mathrm{~kg}$ ( 6 ekor sapi dewasa) dengan periode pengumpulan kotoran selama tiga bulan sekali mencapai $7,4 \mathrm{~kg}$. Jumlah ini dapat disetarakan dengan 16,2 kg urea (46\% nitrogen) (Kaharudin dan Sukmawati, 2010).

Rencana pemecahan masalah tersebut antara lain peningkatan pengetahuan peternak mengenai pengolahan kotoran ternak berupa feses dan urine menjadi pupuk organik padat dan pupuk cair/pestisida cair, penerapan/aplikasi teknologi pengolahan limbah kotoran ternak berupa feses dan urine menjadi pupuk organik padat dan pupuk organik cair/pestisida cair dan pembangunan instalasi biogas sebagai sumber energi.

\section{BAHAN DAN METODE}

Kegiatan pengabdian dilaksanakan di Desa Gedong dan Desa Gemawang, Kecamatan Ngadirojo, Kabupaten Wonogiri. Responden adalah peternak yang tergabung dalam KTT Jati Galih dan KTT Sumber Rejeki yang berasal dari kedua desa tersebut. Metode penentuan lokasi dan responden kegiatan ini ditentukan secara sengaja (purposive sampling) dengan pertimbangan bahwa kedua desa tersebut memiliki populasi ternak sapi potong yang cukup tinggi dan terdapat peternak sapi yang tergabung dalam kelompok KTT Jati Galih dan KTT Sumber Rejeki. Pemilihan secara purposive berarti sampel dipilih dan ditetapkan berdasarkan pertimbangan tertentu yang sesuai dengan tujuan penelitian (Sugiyono, 
2006). Metode kegiatan ini adalah survei untuk mengumpulkan data primer dari responden dan data sekunder dari dinas terkait. Teknik pengumpulan data adalah wawancara, observasi, Focus Group Discussion (FGD), penyuluhan tentang dan pelatihan mengenai pengolahan limbah ternak berbasis bio-slurry menjadi pupuk organik. Analisis data kegiatan ini adalah analisis deskriptif.

Tahapan pelaksanaan kegiatan pengabdian yang digunakan dalam kegiatan ini adalah:

1. Peningkatan pengetahuan mengenai teknologi produksi pupuk organik dan perawatan biogas. Peningkatan pengetahuan peternak melalui kegiatan penyuluhan dan FGD dengan melibatkan instansi terkait, peternak, tokoh masyarakat untuk menggali data agar diperoleh pemecahan masalah yang selama ini dihadapi peternak.

2. Penerapan teknologi produksi pupuk organik. Penerapan teknologi produksi pupuk organik melalui kegiatan pelatihan pembuatan pupuk cair dan padat.

3. Pre-test dan post-test.

Peningkatan pengetahuan peternak setelah mengikuti penyuluhan dan pelatihan diukur dengan cara pre-test dan post-test.

4. Pelaksanaan kegiatan monitoring.

Monitoring dilakukan untuk mengetahui kemajuan dalam kegiatan pelatihan pembuatan pupuk organik dan pembangunan instalasi biogas.

\section{Metode pembangunan instalasi biogas}

Pembangunan digester instalasi biogas meliputi beberapa bagian yaitu inlet sebagai tempat masuknya kotoran ternak, reaktor sebagai ruang pencernaan anaerob, penampung gas, outlet, sistem pengangkut gas dan lubang kompos kotoran ternak/bio-slurry. Pembangunan instalasi biogas tersebut dengan teknologi fixed dome dan kapasitas biogas sebesar $8 \mathrm{~m}^{3}$.

\section{Proses pembuatan pupuk organik cair}

Bahan-bahan yang digunakan dalam proses pembuatan pupuk organik cair adalah urine sebanyak 100 l, empon-empon (lengkuas, temu ireng, jahe, kencur, kunyit, sambiloto, bawang putih, dlingo dan bengle masing-masing sebanyak $1 \mathrm{~kg}$ ), tetes sebanyak 21 dan EM4 $50 \mathrm{ml}$. Semua bahan-bahan dimasukkan satu persatu sambil dilakukan pengadukan. Selanjutnya setiap 2 hari sekali dilakukan pengadukan selama 14 hari.
Setelah 14 hari, pupuk organik cair dapat digunakan.

\section{Proses pembuatan pupuk organik padat}

Limbah biogas/bio-slurry dicampur dengan dolomit/kapur pertanian sebanyak 5-10\%. Selanjutnya diaduk dan didiamkan selama 2-3 hari. Setelah 2-3 hari, pupuk organik padat bisa digunakan sebagai pupuk.

\section{HASIL DAN PEMBAHASAN}

\section{Karakteristik responden}

Karakteristik responden yang mengikuti kegiatan penyuluhan dan pelatihan tentang pembuatan pupuk organik dan biogas antara lain usia responden, jenis kelamin, tingkat pendidikan dan pekerjaan utama.

\section{Usia responden}

Usia responden yang mengikuti kegiatan penyuluhan dan pelatihan di Desa Gedong dan Desa Gemawang tersaji pada Tabel 1.

Tabel 1. Usia responden yang mengikuti kegiatan penyuluhan dan pelatihan

\begin{tabular}{ccc}
\hline $\begin{array}{c}\text { Usia responden } \\
\text { (tahun) }\end{array}$ & $\begin{array}{c}\text { Jumlah responden } \\
\text { (orang) }\end{array}$ & $\begin{array}{c}\text { Persentase } \\
(\%)\end{array}$ \\
\hline$<15$ & 0 & 0,00 \\
$15-30$ & 5 & 15,62 \\
$31-45$ & 7 & 21,88 \\
$46-64$ & 15 & 46,88 \\
$>64$ & 5 & 15,62 \\
\hline Total & 32 & 100,00 \\
\hline
\end{tabular}

Berdasarkan Tabel 1 menunjukkan bahwa rata-rata peternak yang mengikuti penyuluhan dan pelatihan berusia produktif dengan kategori usia 46-64 tahun sebanyak 15 orang $(46,88 \%)$. Hal ini sesuai pendapat Prabayanti (2010) bahwa kelompok berusia produktif yaitu usia 15 sampai 64 tahun dan kelompok berusia tidak produktif yaitu usia lebih dari 64 tahun. Peternak di Desa Gemawang dan Desa Gedong yang berusia produktif memiliki kemampuan fisik yang baik dan pemikiran yang luas dalam mengembangkan usahanya. Seseorang yang berusia produktif mempunyai kondisi fisik, tindakan serta kemampuan berfikir masih cukup baik (Setiana, 2000). Menurut Haerfa (2011) bahwa umur mempengaruhi daya tangkap dan pola pikir seseorang. Semakin bertambah umur manusia maka semakin berkembang pula daya tangkap dan 
pola pikir manusia sehingga pengetahuan yang diperolehnya semakin baik (Prabowo, 2017).

\section{Jenis kelamin responden}

Jenis kelamin peternak yang mengikuti kegiatan penyuluhan dan pelatihan di Desa Gemawang dan Desa Gedong disajikan pada Tabel 2.

Tabel 2. Jenis kelamin peternak yang mengikuti kegiatan penyuluhan dan pelatihan

\begin{tabular}{ccc}
\hline $\begin{array}{c}\text { Jenis } \\
\text { kelamin }\end{array}$ & $\begin{array}{c}\text { Jumlah responden } \\
\text { (orang) }\end{array}$ & $\begin{array}{c}\text { Persentase } \\
(\%)\end{array}$ \\
\hline Laki-laki & 18 & 56,25 \\
Perempuan & 14 & 43,75 \\
\hline \multicolumn{1}{c}{ Total } & 32 & 100,00 \\
\hline
\end{tabular}

Berdasarkan Tabel 2 menunjukkan rata-rata peternak yang mengikuti kegiatan penyuluhan dan pelatihan berjenis kelamin laki-laki sebanyak 18 orang dengan persentase 56,25\%. Usaha peternakan memerlukan kemampuan fisik yang baik agar usaha berjalan dengan lancar. Laki-laki memiliki kemampuan fisik yang lebih baik daripada perempuan dan memiliki tanggungjawab yang besar di dalam keluarganya. Hal ini sesuai pendapat Priyanto (2008) bahwa umumnya lakilaki lebih bisa memegang tanggung jawab yang besar terhadap suatu pekerjaan dibandingkan perempuan.

\section{Tingkat pendidikan responden}

Tingkat pendidikan responden kegiatan penyuluhan dan pelatihan di Desa Gemawang dan Desa Gedong dapat dilihat pada Tabel 3.

Tabel 3. Tingkat pendidikan responden yang mengikuti kegiatan penyuluhan dan pelatihan

\begin{tabular}{lcc}
\hline $\begin{array}{c}\text { Tingkat } \\
\text { pendidikan }\end{array}$ & $\begin{array}{c}\text { Jumlah responden } \\
\text { (orang) }\end{array}$ & $\begin{array}{c}\text { Persentase } \\
(\%)\end{array}$ \\
\hline SD & 19 & 59,38 \\
SMP & 8 & 25,00 \\
SMA & 4 & 12,50 \\
Diploma & 0 & 0,00 \\
Sarjana & 1 & 3,12 \\
\hline \multicolumn{1}{c}{ Total } & 32 & 100,00 \\
\hline
\end{tabular}

Berdasarkan Tabel 3 menunjukkan bahwa rata-rata peternak berpendidikan rendah yaitu $\mathrm{SD}$ sebanyak 19 orang dengan persentase 59,38\%. Rendahnya pendidikan peternak menyebabkan usaha peternakan kurang berkembang dengan baik karena keterbatasan pengetahuan dan ketrampilan peternak dalam menerapkan inovasi pada usahanya. Hal ini sesuai pendapat Sutawi (2007) bahwa semakin tinggi tingkat pendidikan peternak maka semakin cepat juga dalam melaksanakan adopsi inovasi dan semakin rendah tingkat pendidikan maka pelaksanaan adopsi inovasi juga semakin lambat.

\section{Pekerjaan utama responden}

Pekerjaan utama responden yang mengikuti kegiatan penyuluhan dan pelatihan di Desa Gemawang dan Desa Gedong tersaji pada Tabel 4.

Tabel 4. Pekerjaan utama responden yang mengikuti kegiatan penyuluhan dan pelatihan

\begin{tabular}{lcc}
\hline $\begin{array}{c}\text { Tingkat } \\
\text { pendidikan }\end{array}$ & $\begin{array}{c}\text { Jumlah responden } \\
\text { (orang) }\end{array}$ & $\begin{array}{c}\text { Persentase } \\
(\%)\end{array}$ \\
\hline Petani & 16 & 50,00 \\
Peternak & 1 & 3,13 \\
Wiraswasta & 2 & 6,25 \\
Swasta & 1 & 3,13 \\
Buruh & 2 & 6,25 \\
Ibu rumah & 7 & 21,87 \\
tangga & & \\
Perangkat desa & 1 & 3,13 \\
Pande/empu & 1 & 3,13 \\
PNS & 1 & 3,13 \\
\hline \multicolumn{1}{c}{ Total } & 32 & 100,00 \\
\hline \multicolumn{2}{r}{}
\end{tabular}

Berdasarkan Tabel 4 menunjukkan bahwa responden memiliki pekerjaan utama sebagai petani yaitu sebanyak 16 orang dengan persentase $50 \%$. Usaha peternakan merupakan sebagai usaha sampingan untuk menambah pendapatan responden. Menurut Budiraharjo et al. (2011) dan Mulyo et al. (2012), bahwa peternak beternak sapi potong selain untuk mendapatkan keuntungan, juga sebagai tabungan apabila membutuhkan uang dan memanfaatkan kotoran ternak untuk usahataninya.

\section{Pelaksanaan kegiatan pelatihan dan penyuluhan}

Kegiatan penyuluhan dan pelatihan disampaikan oleh narasumber dengan materi meliputi perawatan biogas dan pengolahan limbah kotoran ternak menjadi pupuk organik (Gambar 1 dan Gambar 2). Penyuluhan dan pelatihan dilaksanakan di Desa Gemawang, Kecamatan Ngadirojo dengan dihadiri peternak dari anggota KTT Jati Galih dan KTT Sumber Rejeki serta dari dinas terkait dan pemerintah desa. 


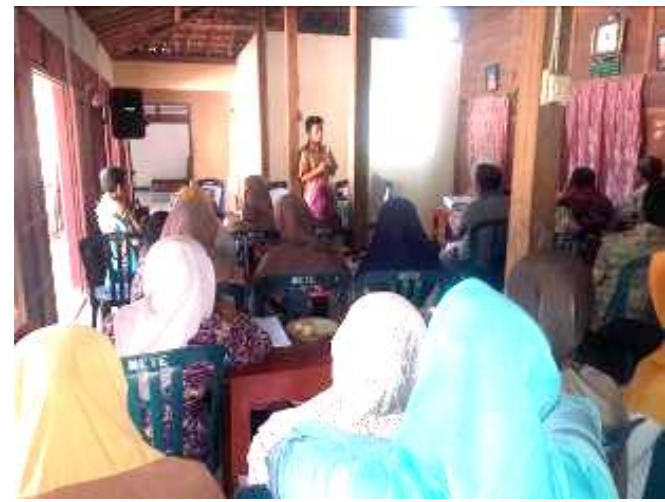

Gambar 1. Penyampaian materi oleh narasumber

Peternak sebelum mendapatkan materi dari para narasumber diberikan pre-test untuk mengetahui pengetahuan awal dari peternak dan diberikan post-test untuk mengetahui peningkatan pengetahuan peternak setelah diberikan materi dan mengikuti pelatihan pembuatan pupuk organik dari limbah kotoran ternak sapi dan biogas (Gambar 3). Berdasarkan hasil nilai pretest dan pos-test menunjukkan bahwa terjadi peningkatan pengeta-huan peternak seperti tersaji pada Tabel 5.

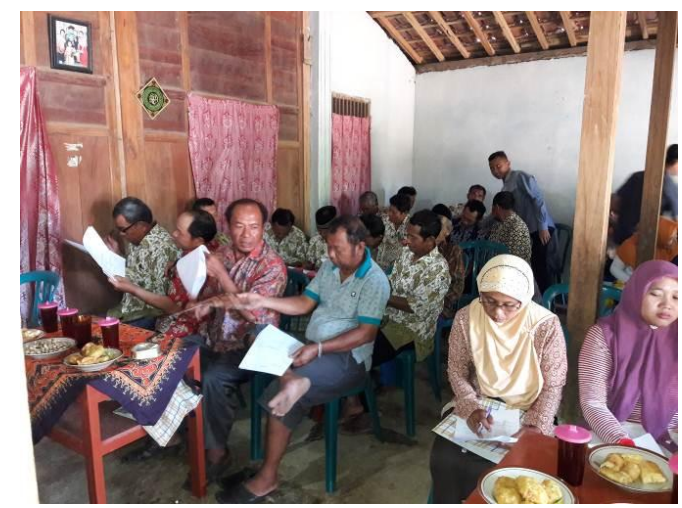

Gambar 3. Peternak mengerjakan pre-test sebelum mendapatkan materi

Menurut Marlina et al. (2019), salah satu pengukuran adanya peningkatan pengetahuan dan keterampilan peserta adalah melalui analisis perubahan antara nilai pre-test dan post-test. Ditinjau dari nilai pre-test menunjukkan bahwa rata-rata pengetahuan awal tentang pupuk organik dan biogas responden masih relatif rendah yaitu rata-rata 59,88. Responden setelah mengikuti kegiatan penyuluhan dan pelatihan terjadi peningkatan pengetahuan yaitu sebesar 12,50 dengan nilai post-test sebesar 72,38. Hal ini menunjukkan bahwa proses transfer pengetahuan

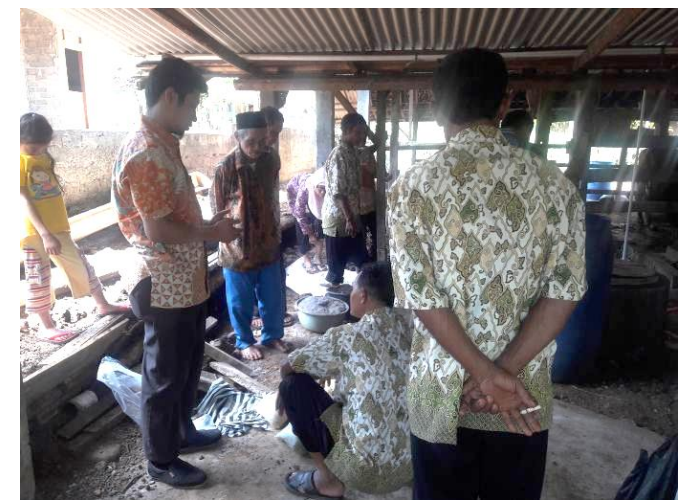

Gambar 2. Praktek pembuatan pupuk organik

dan keterampilan pengolahan limbah ternak cukup baik (Marlina et al., 2019).

Tabel 5. Peningkatan pengetahuan peternak

\begin{tabular}{cccc}
\hline $\begin{array}{c}\text { Nomor } \\
\text { responden }\end{array}$ & $\begin{array}{c}\text { Nilai } \\
\text { pre-test }\end{array}$ & $\begin{array}{c}\text { Nilai } \\
\text { post-test }\end{array}$ & $\begin{array}{c}\text { Peningkatan } \\
\text { pengetahuan }\end{array}$ \\
\hline 1 & 62,86 & 53,33 & $-9,52$ \\
2 & 48,57 & 34,29 & $-14,29$ \\
3 & 67,62 & 43,81 & $-23,81$ \\
4 & 72,38 & 62,86 & $-9,52$ \\
5 & 77,14 & 86,67 & 9,52 \\
6 & 77,14 & 110,48 & 33,33 \\
7 & 81,90 & 86,67 & 4,76 \\
8 & 34,29 & 39,05 & 4,76 \\
9 & 34,29 & 43,81 & 9,52 \\
10 & 39,05 & 39,05 & 0,00 \\
11 & 34,29 & 58,10 & 23,81 \\
12 & 34,29 & 43,81 & 9,52 \\
13 & 53,33 & 77,14 & 23,81 \\
14 & 67,62 & 81,90 & 14,29 \\
15 & 67,62 & 67,62 & 0,00 \\
16 & 43,81 & 62,86 & 19,05 \\
17 & 58,10 & 72,38 & 14,29 \\
18 & 72,38 & 81,90 & 9,52 \\
19 & 72,38 & 81,90 & 9,52 \\
20 & 72,38 & 105,71 & 33,33 \\
21 & 39,05 & 77,14 & 38,10 \\
22 & 58,10 & 91,43 & 33,33 \\
23 & 58,10 & 91,43 & 33,33 \\
24 & 62,86 & 110,48 & 47,62 \\
25 & 62,86 & 77,14 & 14,29 \\
26 & 53,33 & 67,62 & 14,29 \\
27 & 86,67 & 91,43 & 4,76 \\
28 & 81,90 & 96,19 & 14,29 \\
29 & 62,86 & 96,19 & 33,33 \\
30 & 81,90 & 81,90 & 0,00 \\
31 & 39,05 & 48,57 & 9,52 \\
32 & 58,10 & 53,33 & $-4,76$ \\
\hline Rata-rata & 59,88 & 72,38 & 12,50 \\
\hline & & & \\
& & & \\
16 & &
\end{tabular}


Pembangunan dan pemasangan instalasi biogas

Pembangunan dan pemasangan Instalasi Biogas dilakukan di mitra KTT Sumber Rejeki, Desa Gemawang dikarenakan jumlah kepemilikan ternak lebih sedikit daripada di mitra KTT Jati Galih sehingga besaran kapasitas pemba-

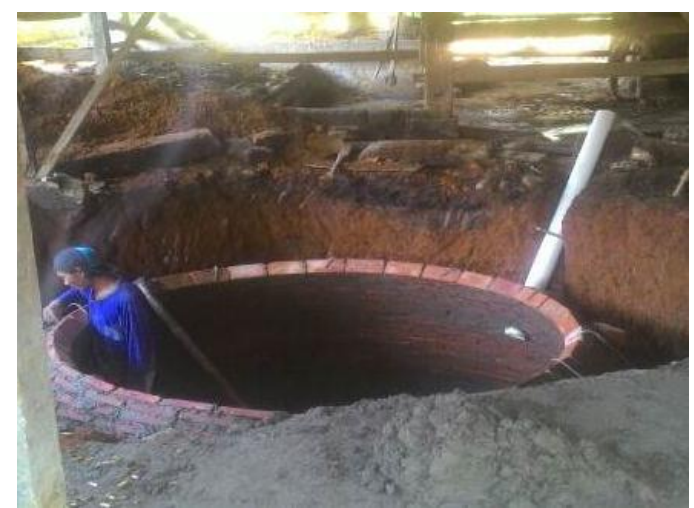

Gambar 4. Pembangunan instalasi biogas

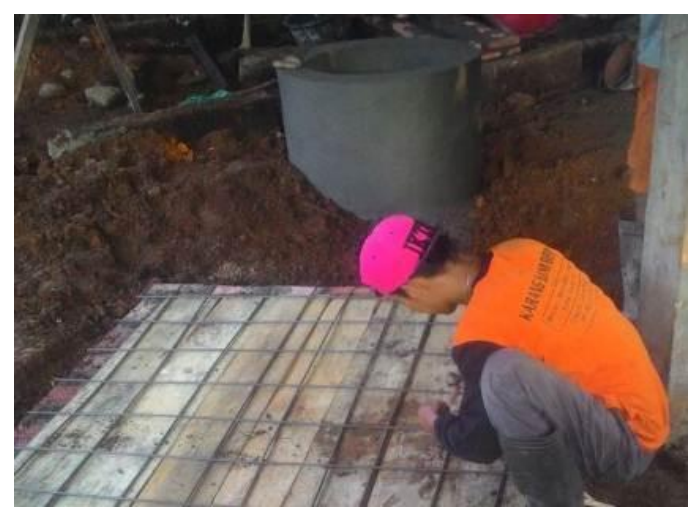

Gambar 6. Penutup biogas

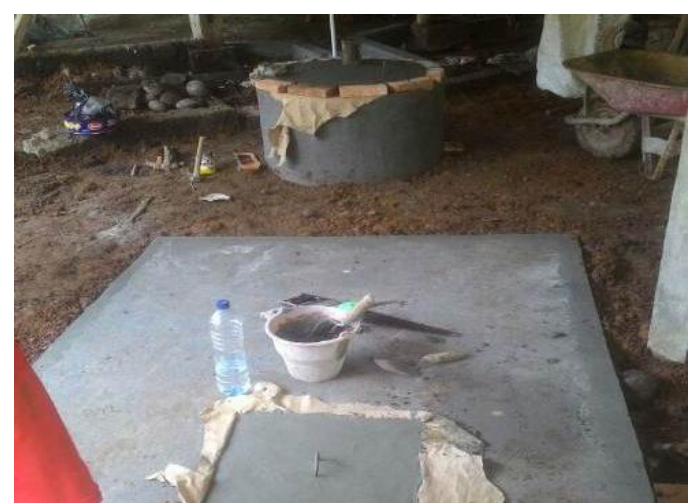

Gambar 8. Pembangunan instalasi biogas yang telah jadi/selesai

Pembangunan instalasi biogas di mitra KTT Sumber Rejeki, Desa Gemawang memberikan manfaat kepada peternak dikarenakan dengan adanya instalasi biogas mengurangi pengeluaran ngunan instalasi biogas menyesuaikan jumlah ternak yang dimiliki oleh peternak yaitu dengan kapasitas biogas sebesar $8 \mathrm{~m}^{3}$ dan teknologi fixed dome. Gambaran pembangunan dan pemasangan instalasi biogas bisa dilihat pada Gambar 4, Gambar 5, Gambar 6, Gambar 7, Gambar 8 dan Gambar 9.

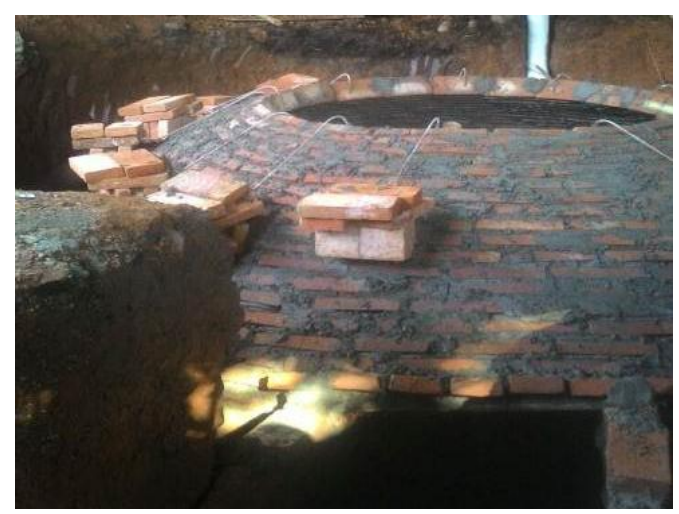

Gambar 5. Pembangunan kubah

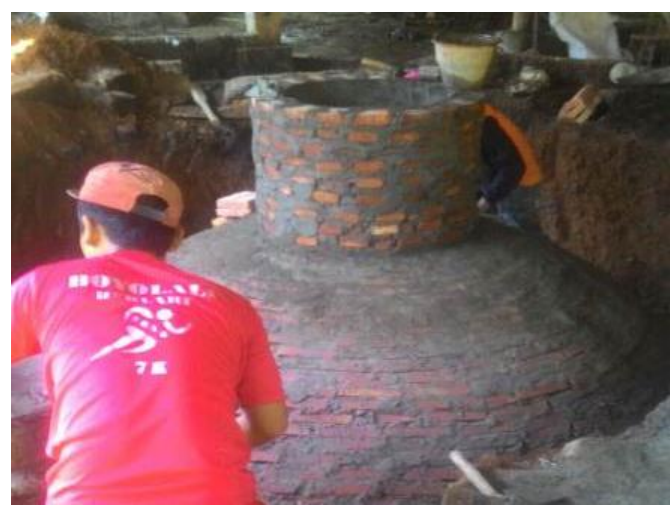

Gambar 7. Penyelesaian kubah

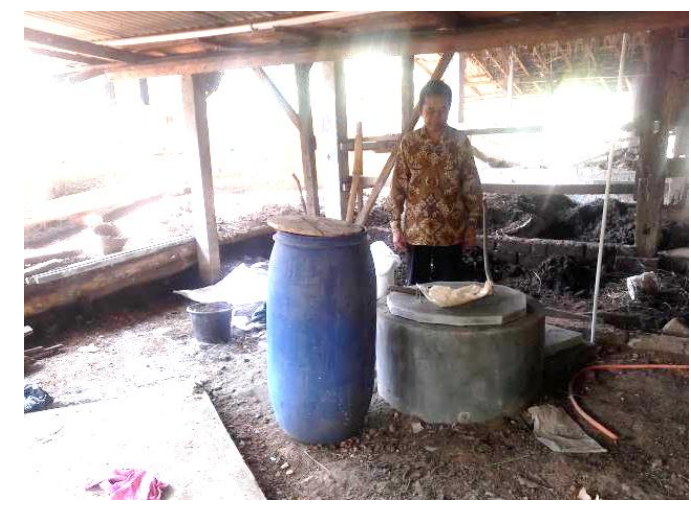

Gambar 9. Instalasi biogas di Desa Gemawang

untuk pembelian bahan bakar gas sehingga pendapatan peternak meningkat (Gambar 10). Menurut Kaharudin dan Sukmawati (2010), produk akhir dari biogas adalah gas metana yang 
dapat dimanfaatkan untuk mendukung kehidupan masyarakat. Manfaat tersebut sifatnya ada yang langsung dapat digunakan baik sebagai sumber energi maupun manfaat tidak langsung yang dapat mendukung sektor lain. Manfaat Langsung, antara lain: sebagai sumber energi untuk memasak, sebagai sumber energi untuk penerangan dan penghasil pupuk organik siap pakai dan manfaat tidak langsung, antara lain: mengurangi efek gas rumah kaca, membantu program pelestarian hutan, tanah, dan air, mengurangi polusi bau, meningkatkan sanitasi lingkungan dan keindahan dan mendukung kebijakan pengurangan subsidi Bahan Bakar Minyak (BBM).

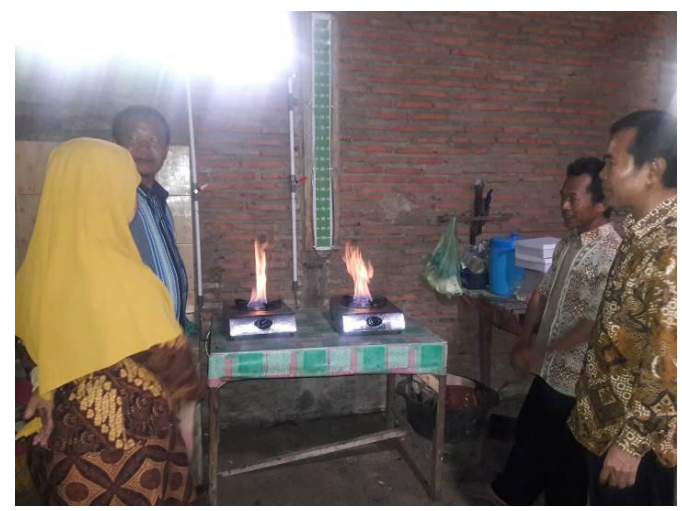

Gambar 10. Instalasi kompor biogas yang telah menyala

\section{Kegiatan monitoring dan evaluasi oleh tim reviewer internal}

Kegiatan Monitoring dan Evaluasi oleh tim Reviewer Internal berjalan lancar, hal ini ditunjukkan oleh semua pelaksanaan kegiatan pengabdian berjalan dengan baik dan peternak merasakan manfaat dengan pembangunan instalasi biogas dan pelatihan pembuatan pupuk organik. Kegiatan monitoring dan evaluasi dapat dilihat pada Gambar 11 dan Gambar 12.

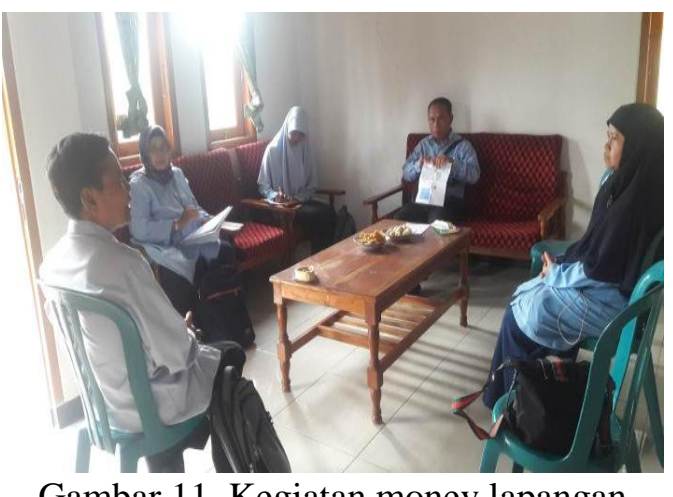

Gambar 11. Kegiatan monev lapangan

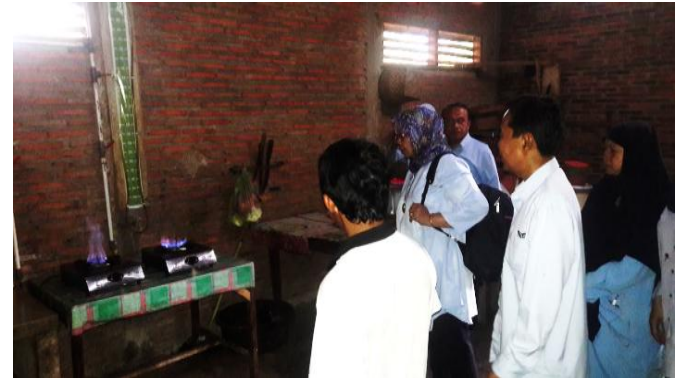

Gambar 12. Kegiatan monev meninjau instalasi biogas

\section{KESIMPULAN}

Kegiatan pengabdian yang telah dilaksanakan memberikan manfaat kepada peternak khususnya dan masyarakat pada umumnya yaitu antara lain peternak menjadi lebih berdaya dikarenakan pengetahuan dan keterampilan peternak meningkat setelah mengikuti penyuluhan dan pelatihan, pendapatan peternak juga lebih meningkat dikarenakan dengan adanya instalasi biogas mengurangi pembelian bahan bakar gas, selain itu pembuatan pupuk organik mengurangi pembelian pupuk kimia.

\section{UCAPAN TERIMA KASIH}

Tim pengabdi mengucapkan terimakasih atas didanainya kegiatan pengabdian dengan skim Program Kemitraan Masyarakat melalui dana PNBP Universitas Sebelas Maret serta kepada masyarakat dan perangkat desa di Desa Gedong dan Gemawang, Ngadirojo, Wonogiri yang telah membantu terlaksananya kegiatan ini sehingga bisa berjalan dengan lancar.

\section{DAFTAR PUSTAKA}

Badan Pusat Statistik Kabupaten Wonogiri. (2016). Kabupaten Wonogiri dalam angka. BPS: Wonogiri.

Budiraharjo, K., Handayani, M., \& Sanyoto, G. (2011). Analisis Profitabilitas Usaha Penggemukan Sapi Potong di Kecamatan Gunungpati Kota Semarang. Mediagro, 7(1), 1-9. Tersedia dari https://publikasiilmiah.unw ahas.ac.id/index.php/Mediagro/article/view/5 $64 / 685$

Haerfa, E. (2011). Pengetahuan dan FaktorFaktor yang Mempengaruhi Pengetahuan. Tersedia dari http://ernest-ha24.blogspot.com/ 
2011/01/pengetahuan-dan-faktor-faktor-yang. html

Kaharudin, \& Sukmawati, F. (2010). Petunjuk Praktis Manajemen Umum Limbah Ternak Untuk Kompos dan Biogas. Balai Besar Pengkajian dan Pengembangan Teknologi Pertaninian: Nusa Tenggara Barat. Tersedia dari https://scholar.google.com/scholar?hl=en \&as_sdt $=0 \% 2 \mathrm{C} 5 \mathrm{\& q}=$ Petunjuk+Praktis+Mana jemen+Umum+Limbah+Ternak+Untuk+Kom pos+Dan+Biogas\&btnG $=$

Marlina, E. T., Hidayati, Y. A., \& Badruzzaman, D. Z. (2019). Pengolahan Terpadu Limbah Ternak di Kelompok Tani Rancamulya Sumedang. Media Kontak Tani Ternak, 1(1), 5-10. https://doi.org/10.24198/mktt.v1i1.215 97

Mulyo, I. T., Marzuki, S., \& Santoso, S. I. (2012). Analisis Kebijakan Pemerintah Mengenai Budidaya Sapi Potong di Kabupaten Semarang. Animal Agriculture Journal, 1(2), 266-277. https://ejournal3.undip.ac.id/index.p hp/aaj/article/view/1277

Prabayanti, H. (2010). Faktor-Faktor yang Mempengaruhi Adopsi Biopeptisida oleh Petani di Kecamatan Mojogedang Kabupaten Karanganyar. Skripsi. Fakultas Pertanian. Universitas Sebelas Maret, Surakarta. Tersedia dari https://scholar.google.com/scholar?hl=en \&as_sdt $=0 \% 2 \mathrm{C} 5 \& \mathrm{q}=$ Faktor-Faktor+yang+ Mempengaruhi+Adopsi+Biopeptisida+oleh+ Petani+di+Kecamatan+Mojogedang+Kabupat en+Karanganyar\&btnG=

Prabowo, D. (2017). Faktor-Faktor yang Berpengaruh terhadap Niat Kewirausahaan Peternak Sapi Potong di Kecamatan Nogosari, Kabupaten Boyolali, Skripsi. Fakultas Pertanian. Universitas Sebelas Maret, Surakarta.
Priyanto, S. H. (2008). Di dalam Jiwa ada Jiwa: The Backbone and the Social Construction of Entrepreneurships. Pidato Pengukuhan Guru Besar Universitas Kristen Satya Wacana, Salatiga. Tersedia dari https://scholar.google. $\mathrm{com} / \mathrm{scholar}$ ?hl=en\&as_sdt=0\%2C5\&q=Di+d alam+Jiwa+ada+Jiwa\%3A+The+Backbone+a nd+the+Social+Construction+of+Entrepreneu rships\&btnG $=$

Lutojo, G., Sihombing, \& Riyanto, J. (2010). Aplikasi Rancang Bangun Instalasi Terpadu Pengolah Limbah Feses dan Urin Untuk Industri Pupuk Organik Padat dan Cair Pada Usaha Penggemukan Sapi Potong. Ipteks Penerapan, Dipa BLU UNS.

Setiana, L. (2000). Dampak Fasilitas Penunjang Usaha Tani terhadap Motivasi Peternak Plasma Ayam Buras di Kabupaten Bantul. Tesis. Peternakan Universitas Gadjah Mada, Yogyakarta. Tersedia dari https://repository. ugm.ac.id/45895/

Sugiyono. (2006). Metode Penelitian Bisnis. Cetakan 9. Bandung: CV Alfabeta.

Susieni, A. (2003). Studi Kelayakan Bisnis. Cetakan 2. Yogyakarta: Andi.

Sunarto, \& Lutojo. (2008). Rancangan Pengolahan dan Produksi Bak Penampung dan Pengolah Pupuk Organik Cair Urin Sapi Berbahan Empon-empon. Program Vucer. DP2M Kemdiknas: Jakarta. Tersedia dari https://opac.perpusnas.go.id/DetailOpac.aspx? id $=9916$

Sutawi. (2007). Agribisnis Peternakan. Kapita Selekta. Universitas Muhammadiyah. Malang: Malang Press. Tersedia dari https://unida.ac. id/elibrary/index.php?p=show_detail\&id=120 $36 \&$ keywords $=$ 